\title{
Characteristics and Effectiveness of Teacher Feedback on Online Business English Oral Presentations
}

\author{
Qi Xu' ${ }^{1}$ (1) Shizhuo Chen ${ }^{3} \cdot$ Jiamin Wang $^{3} \cdot$ Stacy Suhadolc $^{2}$
}

Accepted: 17 May 2021 / Published online: 3 June 2021

(C) De La Salle University 2021

\begin{abstract}
The present study attempted to probe into the role of teacher feedback in an online learning environment during the COVID-19 pandemic. It aimed to investigate the characteristics and effectiveness of teacher feedback on online business English presentations and also to explore EFL learners' attitudes toward teacher feedback. The participants were one class of 24 sophomores majoring in Business English. By analyzing data from transcriptions of teacher feedback on presentation rehearsals, assessment scores, questionnaires, and students' self-reflective journals, the study found that teacher feedback was focused on both content- and delivery-related components, but new sub-components were added to delivery-related teacher feedback, such as technology use, timing, and teamwork. It also proved the positive effect of teacher feedback on improving students' oral presentation quality in various aspects. Additionally, it was found the participants held quite positive attitudes toward teacher feedback. However, some issues also arose in an online learning context. Therefore, pedagogical implications were provided based on the research findings and in response to the challenges of online education.
\end{abstract}

Keywords Teacher feedback - Online education . Oral presentations · Business English

Qi Xu

xqmiracle@gdufs.edu.cn

1 Center for Linguistics and Applied Linguistics, Guangdong University of Foreign Studies, Guangzhou, China

2 Department of Applied Linguistics, The Pennsylvania State University, State College, USA

3 School of English for International Busniess, Guangdong University of Foreign Studies, Guangzhou, China

\section{Introduction}

Oral presentation skills are essential for employability and academic study because they lead students to enter into debate and sustained reasoning. They also enable students to participate fully in their learning, demonstrate their ability to communicate, and help them prepare for their future work (Morley, 2001). Many scholars have conducted research that centered on self- and peer assessment of oral presentations (e.g. Campbell et al., 2001; Cheng \& Warren, 2005) and comparing the effectiveness of peer feedback and teacher feedback (e.g. Murillo-Zamorano \& Montanero, 2018). It was found that teacher feedback could bridge the gap between students' actual and desired performance (De Grez et al., 2012; Ko, 2019) and positively affect students' cognition, behavior and attitude towards presenting (Van Ginkel et al., 2017b). Some other studies proved that a multimedia-based instructional intervention with embedded practice activities and evaluation feedback could enhance the students' oral presentation skills, despite that different dimensions were not affected equally by the multimodal system (De Grez et al., 2009; Ochoa \& Dominguez, 2020; Van Ginkel et al., 2020).

However, as educational environments have changed with rapid development of technology, especially during the COVID-19 pandemic, for EFL students, it seems to be quite challenging to make effective oral presentations without face-to-face communication between the presenters and the audience. Therefore, in online education, the students may require more presentation training practice where explicit, immediate and systematic feedback from external sources (such as experts and peers) could be provided. As a consequence, feedback provided by teachers, regarded as essential moderator or facilitator in online 
learning process, has been attached more importance (Xin \& Feenberg, 2006).

Nevertheless, few attempts have been made to investigate the characteristics of teacher feedback on oral presentations in an online learning environment and the improvements that students make after receiving online teacher feedback (Xu et al., 2017). To address the problems described above, the present study aims to probe into the characteristics and effectiveness of teacher feedback on online business English presentations and also to explore EFL students' attitudes toward teacher feedback.

\section{Literature Review}

\section{Business English Oral Presentations}

The ability to present information effectively is an important skill that higher education students should master (Dunbar et al., 2006). Good presentation skills also offer a particularly competitive advantage to students in business English majors, because it is an essential quality for career success (Bower et al., 2011). However, according to Chan (2011), education experts and employers stress that most undergraduates enter the job market without mastering good oral communication competence, and therefore it is urgent that the training of students' oral presentation skills be incorporated into higher education (Murillo-Zamorano \& Montanero, 2018).

Some previous studies have focused on assessment of oral presentations (e.g. Campbell et al., 2001; Cheng \& Warren, 2005), and teacher and peer feedback on oral presentations (e.g. Murillo-Zamorano \& Montanero, 2018). In recent years, a few scholars have started to investigate the impact of multimedia on the development of student's oral presentation skills (e.g. Ochoa \& Dominguez, 2020; Van Ginkel et al., 2020). They found that the intervention of multimedia could indeed enhance a student's performance, but aspects such as eye contact and the use of filled pauses received progress only with teacher assistance, indicating the important role of teachers in oral presentation training, especially in a multimodal context.

Despite the attempts of integrating multimedia into oral presentation training, little research has been conducted to investigate the process of oral presentations in an online context, where students have to deliver oral presentations by overcoming some technical issues, such as the possible breakdowns of the network connection, a lack of eye contact, and less use of body language. Additionally, a very small number of studies have focused on the presentation process within training and the role of teacher feedback as a way to understand the learning of oral presentation skills (Elfering et al., 2012); even less attention has been paid to a business English context.

\section{Teacher Feedback on Oral Presentations}

Teacher feedback is defined as information that describes a student's performance in a given activity provided by the teacher, aiming to guide students to make improvements in the same or related activity (Hattie \& Timperley, 2007). Accurate teacher feedback can improve calibration and guide students to revise their performance of presentation (Stone, 2000). Since the outbreak of COVID-19 pandemic has led to wide-spread online education globally, it is of greater necessity to probe into teacher feedback on oral presentations in an online learning context.

Previous studies have proven the positive effects of teacher feedback on oral presentations, which have resulted in higher-quality performances, and helped students develop communication, technical, and transferable skills, especially in terms of how to clearly express their ideas (De Grez et al., 2009). Some studies also found that the students showed positive attitude towards teacher feedback because of its specific and non-directive nature (Van Ginkel et al., $2017 b$ ). In online education, teacher feedback is also one important educational mediation tool. Students not only gain a convenient opportunity for immediate feedback from the teachers, but also benefit from it in terms of their perceptions, language output, learning process, and performance (Ko, 2019). Many studies have found that the technology-aided teacher feedback was highly welcomed by students and confirmed to facilitate speaking abilities (Xu \& Peng, 2017; Hwang et al., 2016). However, little is known about the effectiveness of and students' attitudes toward teacher feedback on oral presentations in an online context.

In terms of the content of teacher feedback on oral presentations, according to De Grez et al. (2012), it should be based on the assessment rubric, which includes contentrelated criteria (e.g. quality of introduction, structure, and conclusion) and delivery-related criteria (e.g. eye contact, body language, and interaction with audience). Wang et al. (2017) explored a Chinese EFL teacher's feedback on students' oral presentations. They found the teacher gave comments mainly on pronunciation, content, logical thinking, and PowerPoint design, but ignored such aspects as eye contact and vocal delivery. They also found that the teacher used the 'praise-criticism-suggestion' pattern to give feedback. Although the study only interviewed one teacher and lacked the analysis of the students' performance and corresponding teacher feedback, it explored the specific aspects that teacher feedback of oral presentations focused on. Regarding online presentations, it would be 
interesting to explore how teacher feedback could be modified to adapt to an online learning environment.

\section{Research Gaps and Research Questions}

Although some research has been conducted to investigate teacher feedback on oral presentations, still little is known about how teachers give online feedback on EFL students' oral presentations and its specific characteristics (Wang et al., 2017). Moreover, few studies have targeted the training of business English oral presentations, which require a combination of presentation skills and business knowledge. In addition, there is a lack of research making qualitative comparison of the EFL students' performance in giving online oral presentations before and after receiving teacher feedback, so as to examine the effectiveness of teacher feedback for improving students' online oral presentation ability. Furthermore, little research has been conducted to examine EFL students' attitudes toward online teacher feedback. The students' attitudes represent their preference for instructional interventions. When students express positive attitudes, their participation may increase, thus leading to greater progress in language learning (Xu et al., 2017).

Based on the literature review and research gaps mentioned above, three research questions are put forward:

(1) What are the characteristics of teacher feedback provided to students' online business English oral presentations?

(2) What improvements do the students make of online oral presentations after receiving teacher feedback?

(3) What attitudes do the students have toward the teacher feedback on their online oral presentations?

\section{Methodology}

\section{Context of the Study}

The business oral presentations were practiced in a comprehensive business English course at a Chinese university. One of the teaching objectives of the course was to enable students to make effective English oral presentations in business-related situations, and therefore each semester all students were required to give business English oral presentations as an assignment that took up $20 \%$ of their final scores. However, due to the outbreak of COVID-19, all classes had to be given online during the 2019-2020 second semester. With this background, students were required to give online oral presentations via Tencent Meeting, a professional video conferencing system widely used in China. As a result, some new challenges were posed to both the teacher and students, regarding the use of technology, online interaction, group cooperation, assessment, and feedback provision.

\section{Participants}

One class of 24 sophomores (20 females and four males) majoring in Business English participated in the study. They were intermediate EFL learners and divided into six groups based on their own choice. In the first year of their study, they had accumulated some experience in giving English oral presentations, but received little systematic training on presentation skills. None of the students had given online oral presentations before the study. The results of a pre-study questionnaire show that a great majority of the students considered teacher feedback on their oral presentations quite necessary. All students had signed a consent form and were confirmed that all their responses to the research would remain anonymous without influencing their course scores.

The first author was the course teacher, who held a $\mathrm{Ph} . \mathrm{D}$. degree in applied linguistics and had 7-year experience of teaching the course. She had abundant experience in guiding students to give business oral presentations and offering constructive feedback. She was also familiar with the use of the online platform.

\section{Research Procedure}

The study followed a 4-step procedure, including students' preparation, rehearsal with the teacher, students' revision, and live presentation during the online class (see Table 1). Detailed teacher feedback was provided in Step 2, when students presented their rehearsals to the teacher three days before live class. The focus of the study was to examine the characteristics of teacher feedback given at this stage, and investigate whether teacher feedback was facilitative for improving students' oral presentations in online live class. What follows is more specifics for each step.

\section{Step 1. Preparation}

First of all, each group prepared an oral presentation based on a business topic (see the instructions in Fig. 1). They were asked to explain, analyze, and evaluate the business topic with reference to the requirements of Bloom's Taxonomy (Krathwohl, 2002), because it targets the development of critical thinking skills and conforms to the learning objectives of the course. 
Table 1 Procedure of students' oral presentations

\begin{tabular}{lll}
\hline Tasks & Details \\
\hline Step 1 & Students' preparation & $\begin{array}{c}\text { Students decided on a specific business topic and prepared oral presentations based on instructions } \\
\text { Step 2 }\end{array}$ \\
$\begin{array}{c}\text { Rehearsal with } \\
\text { teacher }\end{array}$ & $\begin{array}{c}\text { Students gave a presentation rehearsal during online meeting with the teacher, who then offered detailed } \\
\text { feedback }\end{array}$ \\
Step 3 & Students' revision & Students revised and modified their presentations based on teacher feedback \\
Step 4 & Live presentation & Students gave online presentations during live class, and then received peer and teacher assessment \\
\hline
\end{tabular}

Fig. 1 Online oral presentation instructions
1) Content:
The presentation needs to partly follow Bloom's Taxonomy, and cover:
a) a detailed introduction and explanation of the business news;
b) an analysis of some key information using business-related knowledge;
c) an evaluation of the business news by showing your stand or comments;
d) a summary of 3-5 relevant vocabulary in the business news.
2) Requirements:
a) You ought to work as a team for the presentation;
b) Each presentation lasts 10-15 minutes;
c) You need to use visual aids like power points.
d) You should turn on the camera of your computer while giving presentation.

\section{Step 2. Rehearsal and Teacher Feedback}

Three days before the live presentation in online class, the presenters had an online rehearsal with the teacher, who gave them detailed feedback. According to Van Ginkel et al. (2017a), feedback providers should follow pre-defined assessment criteria and deliver enough detailed information based on sub-criteria. Therefore, the teacher gave feedback on both content and delivery with reference to the assessment criteria (see more details in "Research instruments" section). For the rehearsal of each group, the teacher spent an average of $40 \mathrm{~min}$ commenting on the performance of each group member and giving suggestions for further improvement.

\section{Step 3. Revision}

On the basis of teacher feedback, the presenters needed to revise their presentations in the following aspects: content (e.g. Introduction, Analysis, and Evaluation) and delivery (e.g. PowerPoint making, speaking, group cooperation). The groups then practiced on their own.

\section{Step 4. Online Live Presentation}

At last, one group gave an oral presentation via Tencent Meeting during live class every week. After their presentation, they received peer assessment in both written (through an online questionnaire) and oral forms (through Tencent Meeting). Teacher comments and scores would be provided later.

\section{Research Instruments}

The study adopted a mixed-method approach, including the following sources of data: transcriptions of teacher feedback on presentation rehearsals, presentation assessment scores, questionnaires, and students' self-reflective journals. Both rehearsals and live presentations were recorded to compare the quality of the presentations before and after teacher feedback.

\section{Transcriptions of Teacher Feedback}

The teacher's oral feedback during online presentation rehearsals was recorded and then transcribed by two research assistants. Teacher feedback was given in Chinese, so the transcriptions were later translated into English and coded for research purposes. As mentioned in Step 2 of the research procedure, the teacher gave feedback based on the assessment sub-criteria, therefore, the coding of teacher feedback was closely related to the assessment criteria of business oral presentations in the study. 
De Grez et al. (2012) divided assessment criteria of oral presentation skills into two components, i.e. a content-related component (e.g. introduction, structure, conclusion) and a delivery-related component (e.g. contact with audience, enthusiasm, eye contact, vocal delivery, body language). The study used their assessment criteria as a reference because these scales were applicable for assessing business oral presentations. However, some modifications were made based on the online presentation requirements. The content-related component was adapted corresponding to the structure of the presentations. As for the delivery-related component, visual aids and technology use were added because of the online context; timing and teamwork were also assessed considering it was a group task. Table 2 lists the major components of assessment used in the study. It was also used as the coding scheme of teacher feedback.

\section{Presentation Assessment Scores}

Based on the above assessment criteria, the six groups' business oral presentations were rated by four trained assessors, who were senior postgraduate students majoring in business English studies and who had a rich experience of giving and assessing oral presentations. A five-point Likert scale was used for each sub-criterion (with reference to De Grez et al., 2012). Before the formal assessment, the four assessors were trained by the researchers in terms of assessment criteria. A trial presentation was rated independently by four assessors to make sure they reached a consensus on the interpretation of the assessment criteria and scoring scales. Then all the presentations were rated by the assessors, who were not aware whether they rated a group's rehearsal or live oral presentation and were not told about the research purposes. To further reduce assessor effect, the assessors were divided into two pairs: one pair scored the rehearsals of Groups 1-3 and the live presentations of Groups 4-6; while the other scored vice versa. The average score given by a pair of assessors was the final score for each presentation. The inter-rater reliability

Table 2 Assessment components of business English oral presentations (coding scheme of teacher feedback)

\begin{tabular}{ll}
\hline Content-related component & Delivery-related component \\
\hline Introduction & Visual aids \\
Analysis & Presentation skills \\
Evaluation & Vocal delivery (Speaking) \\
Vocabulary & Technology use \\
& Timing \\
& Teamwork \\
\hline
\end{tabular}

coefficient score (Cronbach alpha: 0.882 for the first pair; 0.874 for the second) showed a high degree of consistency among the assessors. Finally, paired $t$-tests were used to examine whether there was a significant difference between the scores of the rehearsals and the live presentations.

\section{Questionnaires}

A post-study questionnaire was distributed to all the students who remained anonymous for the purpose of examining their attitudes toward giving online business English oral presentations, teacher feedback, and the effectiveness of the teacher feedback. The questionnaire was designed referring to the study conducted by Van Ginkel et al. (2020), and modified based on the research purposes.

\section{Self-Reflective Journals}

After giving the presentation, each presenter was asked to (1) reflect on their own performance by answering the question "In what aspects have you done well and what still needs to be improved?" and (2) write about their attitudes toward teacher feedback (focus of our research): "What have you learned from the teacher feedback, and to what extent do you think the teacher feedback is useful to improve your presentation ability?" The students' reflective journals were coded on the basis of a thematic analysis approach (Boyatzis, 1998) to further reveal their attitudes toward the teacher feedback on online business oral presentations.

\section{Results and Data Analysis}

\section{Characteristics of Teacher Feedback}

Based on the coding results, it was found that only $7 \%$ of the teacher feedback was positive, which included giving students compliments and encouragement. $93 \%$ of the teacher feedback was constructive feedback, which focused on the problems of the oral presentations and providing suggestions for further improvement (Han \& Hyland, 2019). Table 3 is a summary of the teacher's constructive feedback.

The results show that the percentage of delivery-related teacher feedback $(51.6 \%)$ was slightly higher than the content-related components $(48.4 \%)$. For the content-related components, evaluation took up the highest percentage $(20.4 \%)$, followed by analysis $(13.2 \%)$, vocabulary $(9.6 \%)$, and introduction $(6.4 \%)$. A more detailed analysis shows that teacher feedback on content-related items was mainly focused on content demonstration, structure, logic, 
Table 3 Summary of teacher's constructive feedback components

\begin{tabular}{llcc}
\hline Components & Items & Frequency & Proportion (\%) \\
\hline Content & Introduction & 16 & 6.3 \\
& Analysis & 33 & 12.9 \\
& Evaluation & 51 & 19.9 \\
& Vocabulary & 24 & 9.4 \\
\multirow{5}{*}{ Delivery } & Sum & 124 & 48.4 \\
& Visual aids & 62 & 24.2 \\
& Delivery skills & 18 & 7.0 \\
& Technology use & 18 & 7.0 \\
& Speaking & 14 & 5.5 \\
& Timing & 14 & 5.5 \\
& Teamwork & 6 & 2.3 \\
& Sum & 132 & 51.6 \\
\hline
\end{tabular}

and business knowledge. Table 4 lists some typical examples of content-related teacher feedback.

With regard to the delivery-related components, most attention was paid to visual aids $(24.8 \%)$, i.e. PowerPoint slides made for the presentations. After further analysis of the teacher feedback on visual aids, items such as animation, word font, pictures, language use, and structure were found to be frequently used. In addition, presentation skills (e.g. demonstration, interaction with audience, eye contact), speaking (e.g. pronunciation, pace, fluency), technology use (e.g. camera positioning, network, PowerPoint sharing), timing, and teamwork were also included in the teacher feedback on delivery-related components. What follows are examples of delivery-related teacher feedback (Table 5).

\section{Comparison Between the Rehearsals and Live Presentations}

The students' scores of rehearsals and live presentations were calculated and then compared to investigate whether the students' overall performance improved after receiving teacher feedback. Results show that all of the groups' scores increased, to a greater or lesser degree. It can be seen in Table 6 that paired $t$-test results show a significant difference between the scores of the rehearsals and live presentations $(t=7.269, p<.001)$. The mean score of the live presentations $(M=39, \mathrm{SD}=1.788)$ was significantly higher than that of the rehearsals $(M=34.5, \mathrm{SD}=1.225)$. It indicates that the quality of the students' oral presentations improved substantially after the provision of teacher feedback.

In order to discover the specific aspects in which the students had improved, detailed scores were calculated with regard to content and delivery-related sub-criteria. The results show that the scores for all of the sub-criteria increased from rehearsals to live presentations. The mean score of the content-related components increased by two points (from 14.33 to 16.33). As shown in Fig. 2, the most obvious improvements were observed in analysis (with an increase of 0.84 points), followed by introduction $(0.50$ points).

As for the delivery-related components, the mean score rose by 2.5 points (from 20.17 to 22.67). Students made more progress in terms of visual aids, technology use, and speaking, with an increase of 0.50 points, respectively (see Fig. 3). However, the mean scores of delivery-related subscales were still relatively lower than those of contentrelated components, especially in the aspects of speaking (3.33), delivery skills (3.67) and technology use (3.67).

To further illustrate the improvement of students' online oral presentations, a case analysis of Group 4 was

Table 4 Examples of content-related teacher feedback

\begin{tabular}{|c|c|c|c|}
\hline & Items & Details & Examples \\
\hline 1 & Introduction & Lead-in & $\begin{array}{l}\text { The topic is about the reviving of the street vendor economy in China, but you talked a lot about the long } \\
\text { history of street vendors. Remember to give the audience a quick lead-in by introducing the overall } \\
\text { situation. (Group 6) }\end{array}$ \\
\hline 2 & Analysis & $\begin{array}{l}\text { Business } \\
\text { knowledge }\end{array}$ & $\begin{array}{l}\text { You mentioned the concept of MCNs (Multi-channel Network) in your analysis. Have you learned about the } \\
\text { concept in other courses? No, so this is relatively new knowledge for your classmates. You need to explain } \\
\text { it a little more so that the audience can understand it. (Group 4) }\end{array}$ \\
\hline 3 & Evaluation & Structure & $\begin{array}{l}\text { Now it's not clear how many parts you have divided in Evaluation, so I suggest that you label 1, 2, } 3 \text { for } \\
\text { different parts. It's really confusing if you don't give it labeling. (Group 3) }\end{array}$ \\
\hline 4 & Evaluation & $\begin{array}{l}\text { Critical } \\
\text { thinking }\end{array}$ & $\begin{array}{l}\text { You're still making an objective analysis until here, but I hope you could show your own opinions about } \\
\text { internet celebrities and add your own comments on the internet celebrity economy, including some possible } \\
\text { negative influences. (Group 4) }\end{array}$ \\
\hline 5 & Vocabulary & Word selection & $\begin{array}{l}\text { I don't think that it's necessary to explain the phrase "live streaming" in Vocabulary, for the audience are } \\
\text { quite familiar with it. Try to find other phrases that can add some new business knowledge. (Group 5) }\end{array}$ \\
\hline
\end{tabular}


Table 5 Examples of delivery-related teacher feedback

\begin{tabular}{|c|c|c|c|}
\hline & Items & Details & Examples \\
\hline 1 & Visual aids & Animation & $\begin{array}{l}\text { You covered a lot of information in this part, but you didn't use any animation on your power point. It's } \\
\text { quite overwhelming to the audience. You need to use animation to present the key information step by } \\
\text { step. For example,... (Group 5) }\end{array}$ \\
\hline 2 & $\begin{array}{l}\text { Presentation } \\
\text { skills }\end{array}$ & $\begin{array}{l}\text { Interaction with } \\
\text { audience }\end{array}$ & $\begin{array}{l}\text { Here are four pictures of internet celebrities and food products, so you could actually interact with the } \\
\text { audience by asking them questions like "have you bought anything via live streaming?" (Group 1) }\end{array}$ \\
\hline 3 & Speaking & Pronunciation & $\begin{array}{l}\text { X (student name), please pay special attention to the pronunciation of "analyze". You pronounced it as } \\
\text { "analysis" all the time. (Group 4) }\end{array}$ \\
\hline 4 & $\begin{array}{l}\text { Technology } \\
\text { use }\end{array}$ & Camera & $\begin{array}{l}\text { Y (student name), I can't see your face clearly. You need to adjust the angle of the camera to show your } \\
\text { entire face. (Group 2) }\end{array}$ \\
\hline 5 & Timing & Time allocation & $\begin{array}{l}\text { You only spent } 2.5 \text { min on Evaluation. It's far from enough. Evaluation is a key component of the } \\
\text { presentation, so it should take around } 4 \text { min. (Group 5) }\end{array}$ \\
\hline 6 & Teamwork & Group cooperation & $\begin{array}{l}\text { It seems that you worked on your own, rather than cooperating with each other. The content of } \\
\text { Evaluation was separated from Analysis. Check all the sections as a team and make it coherent. (Group } \\
\text { 2) }\end{array}$ \\
\hline
\end{tabular}

Table 6 Statistical results of online presentation assessment

\begin{tabular}{lllll}
\hline & Mean & SD & $t$ value & $p$ value \\
\hline Rehearsals & 34.5 & 1.225 & 7.269 & $<.001$ \\
Live presentations & 39 & 1.788 & & \\
\hline
\end{tabular}

conducted to demonstrate how teacher feedback positively influenced students' performance in live presentations. The presentation topic of Group 4 was the business model of a popular Chinese internet celebrity. In the analysis part, the presenter mentioned a lot of business knowledge that was unfamiliar to the audience. Without clear explanation, it was quite difficult for other students to understand the analysis of the business model within 3-4 min.

In response to the problems, some suggestions were given by the teacher that the Chinese translations of some key words be added (see Fig. 4) and the detailed calculation of income be simplified (see Fig. 5). After the modification, the PowerPoint of the analysis part also became more audience-friendly, accompanied with some explanations of the keywords and reduced cognitive burden for the audience.

\section{Students' Attitudes Toward Teacher Feedback}

Results from the post-study questionnaire reveal $91.67 \%$ of the students enjoyed or quite enjoyed giving online business English presentations and $87.5 \%$ showed their confidence in completing the task. All students considered it necessary to have a rehearsal with the instructor (with an average score of 5.63 out of 6), and all of them enjoyed receiving teacher feedback on their online oral presentations (5.67). In addition, all of the students agreed that teacher feedback was quite useful for improving their oral presentation abilities (5.65).
In the students' reflective journals, the majority of them emphasized the important role of teacher feedback in improving the quality of their online oral presentations. Many of the students expressed their gratitude to the teacher's feedback in rehearsals, stating that the teacher pointed out their problems they had never realized before. For instance, one student wrote that "The teacher suggested we had better use more animation to present the complex content, rather than put too much information on the PowerPoint at once. It was very useful advice, so we modified our power point accordingly." Some mentioned that the business English presentations made online were of higher quality than those given in classrooms, because the content was more engaging, the explanation was clearer, and the visual aids were used more appropriately.

However, certain problems also arose due to a lack of face-to-face interaction and the restrictions of online communication. For example, some students commented that the efficiency of online presentations was lower because the presenters were not able to notice the audience's facial expressions, thus lacking a sense of mutual communication; some presenters mainly read from their scripts instead of expressing them naturally. In the online learning context, these problems are not easily solved, but they may be compensated by more professional guidance from the teacher.

\section{Discussion and Conclusion}

Due to the outbreak of COVID-19, a series of educational resources need to be re-allocated and adjusted to catering for the needs of online education. The present study was an attempt to probe into the role of teacher feedback in an online learning context. The study revealed the 
Fig. 2 Mean scores of contentrelated components

\section{Content-related components}

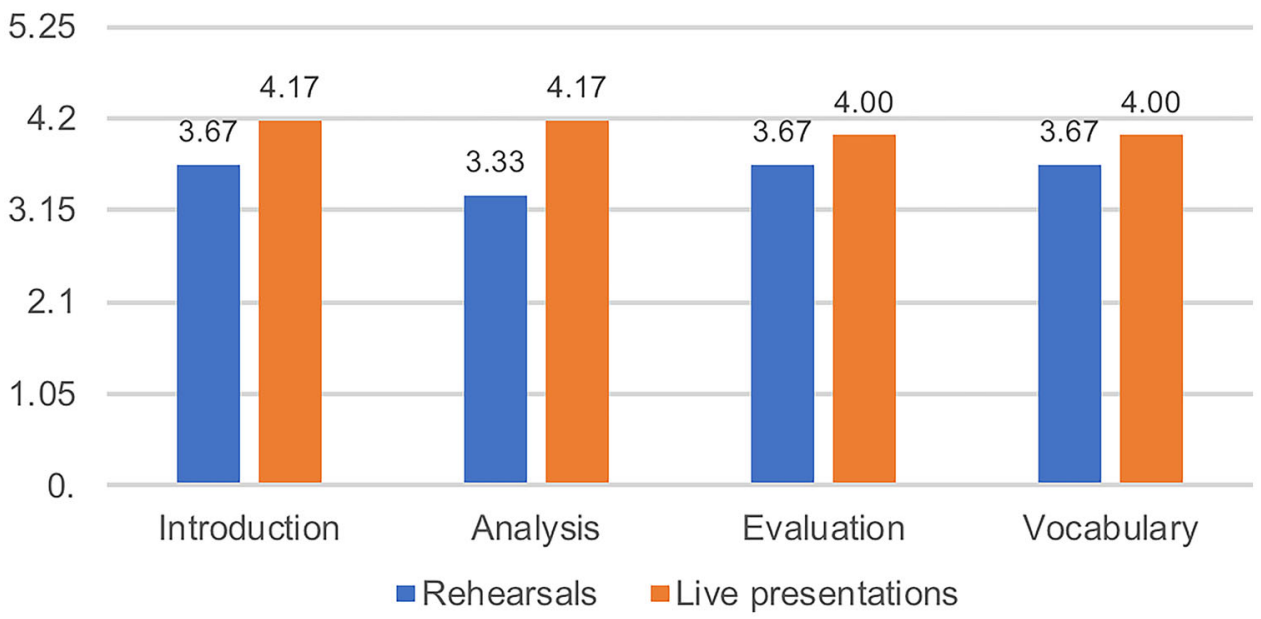

Fig. 3 Mean scores of delivery-related components

Delivery-related components

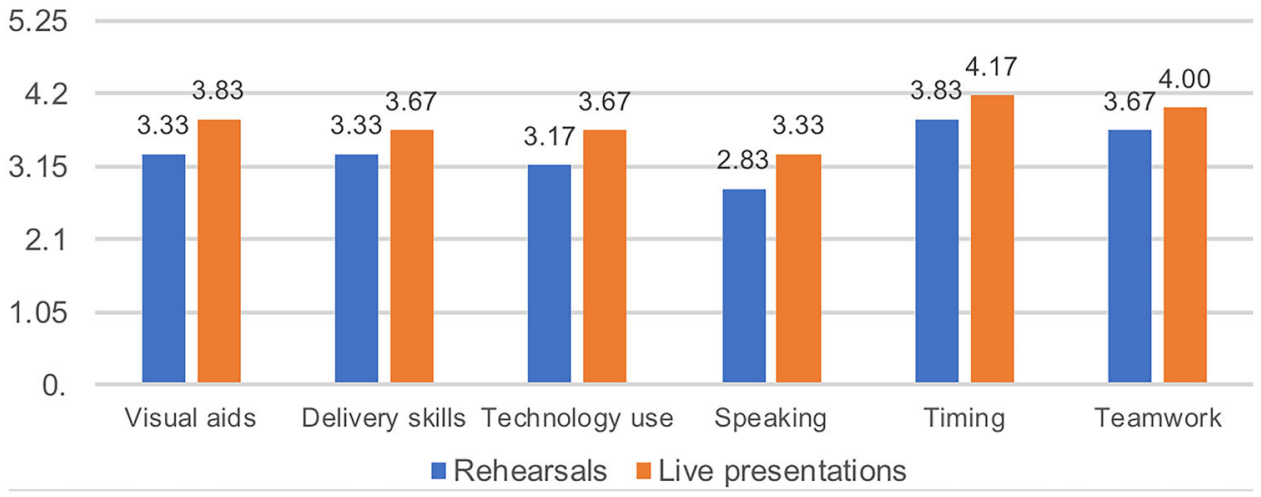

characteristics of teacher feedback on EFL students' online business English presentations, and proved the positive effect of teacher feedback on improving students' oral presentation abilities in various aspects. Additionally, it was found that the participants held quite positive attitudes toward teacher feedback and agreed on the effectiveness of teacher feedback for improving their online oral presentation abilities.

Similar to previous studies (e.g. De Grez et al., 2012; Van Ginkel et al., 2017a), teacher feedback of the study was also focused on both content and delivery-related components. For content-related teacher feedback, it was closely connected with the business-relevant presentation materials, which followed the requirements of Bloom's Taxonomy (Krathwohl, 2002). However, unlike face-toface presentations in classrooms, some new sub-components were added to delivery-related teacher feedback, such as technology use (e.g. controlling of PowerPoint sharing; making use of the camera), teamwork, and timing to ensure a smooth process of the online presentations. We agree that it is also important for teachers to provide detailed online feedback specifically relevant to pre-defined assessment criteria (Shute, 2008) and target the students' actual performance relative to the assessment sub-criteria of the task (Van Ginkel et al., 2015).

After receiving teacher feedback, the students made great progress in their performance of online oral presentations, as is shown in the significant increase in their assessment scores. The scores rose in both content- and delivery-related aspects. Their improvement was likely attributed to the following reasons. First, detailed constructive teacher feedback was provided to each group, thus affording the students plenty of opportunity to reflect on and revise their presentations. According to Phye and Sanders (1994), specific feedback has been proven to be more effective than general advice. In the students' reflective journals, quite a number of students mentioned that they revised their online presentations based on the 

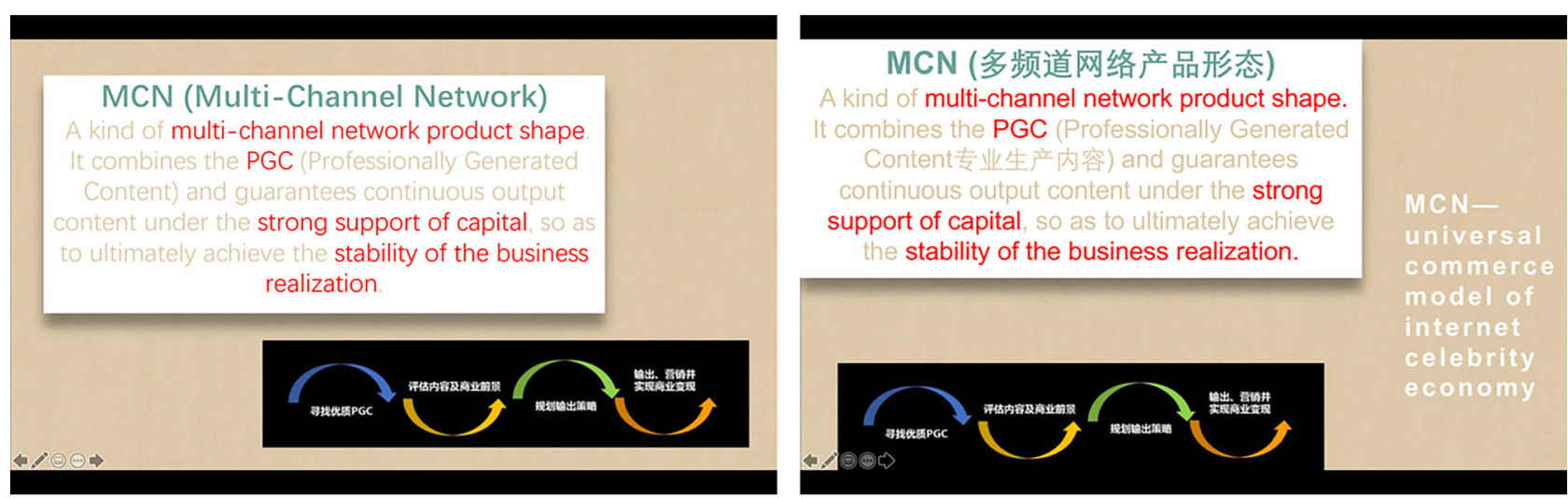

Fig. 4 Comparison of analysis between rehearsal and live presentation (Example 1: Group 4)
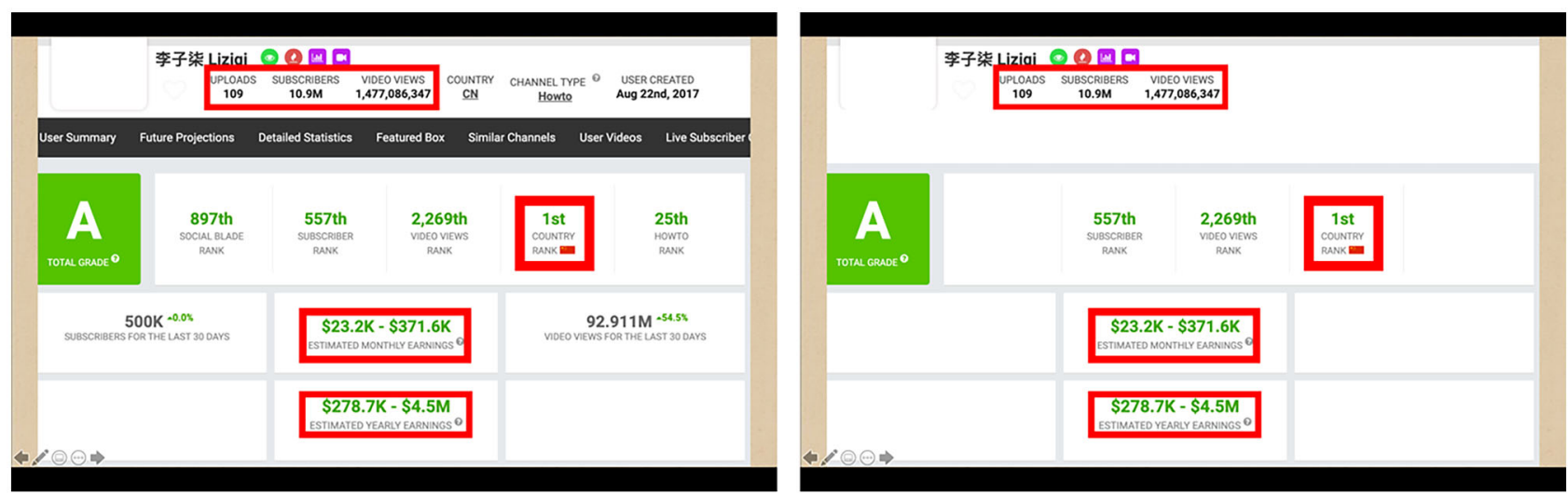

Fig. 5 Comparison of analysis between rehearsal and live presentation (Example 2: Group 4)

teacher's specific feedback, which helped increase the quality of their presentations. Second, teacher feedback was given in an online conferencing session, where the students received immediate feedback that facilitated mutual communication between the teacher and students. Many studies have already suggested that immediate feedback has a greater impact on learning than delayed feedback (Epstein \& Brosvic, 2002). In addition, the students could also gain insights from their peers' presentations and teacher comments in live class, and then apply what they had learned to their own performance.

In spite of the students' positive attitudes toward the online presentation task and teacher feedback, a few issues still remain unsolved and require further exploration. The first issue is concerned with the delivery-related performance, such as the application of visual aids, technology use, presentation skills and manner of speaking. Although great efforts were made to improve the quality of the above-mentioned sub-scales, the mean scores were still lower than those of content-related sub-components. De
Grez et al. (2009, p. 30) also found that the "impact of the instructional intervention was especially useful for the 'content' factor, and performance indicators, such as eye contact and vocal delivery, proved harder to be influenced and/or changed during this short instructional intervention". It is thus suggested that more systematic training on sub-scales be provided to the students to help enhance their delivery-related performance in online education. Apart from delivery, in content-related components, more problems were detected in terms of evaluation, which requires learners to give objective judgment and critical comments. However, the mean score of evaluation did not increase much, probably due to the fact that evaluation was the most difficult part of business oral presentations and needed more professional training.

Another issue is related to the efficiency of online communication. During the process of online presentations, the teacher and presenters were not certain whether the audience paid constant attention to the presentations because not all students turned on their cameras. To ensure 
better communication, it is suggested that some post-task activities be conducted after each presentation, such as giving the audience a chance to ask questions to the presenters and comment on the online presentation.

Our findings may shed light on pedagogical implications in terms of online oral presentations in the following aspects: (1) teachers ought to give specific feedback targeting student's actual performance before online live presentations; (2) special attention needs to be paid to delivery-related sub-components since there is higher demand for delivery quality in an online environment; (3) post-task activities, such as a Q\&A session and peer assessment can be conducted to ensure full participation of all the students.

The present study has filled the research gaps by investigating the specific features and effectiveness of teacher feedback in online oral presentations, but it also has certain limitations. First, only one teacher participated in the study, and therefore the generalizability of the findings is limited. Future research could compare the characteristics of teacher feedback given by the teachers with diversified backgrounds. Second, only one case of the oral presentation was analyzed to explore the improvements made by the students. A more detailed analysis of online oral presentations can be made to further investigate the role of teacher feedback, and also compare the different attributes of online and offline oral presentations. Additionally, the study mainly focused on teacher feedback in online education during the COVID-19 pandemic where no other method of instruction was possible. Future research can incorporate peer feedback and assessment during the online oral presentation task rather than focusing on instructor mediation.

Ackowledgements This research was supported by the Humanities and Social Science Research Foundation of the Ministry of Education of China (Grant Number 18YJC740120) and the Outstanding Young Talents Training Project in Guangdong Province, China (Grant Number 2017WQNCX041).

\section{References}

Bower, M., Cavanagh, M., Moloney, R., \& Dao, M. (2011). Developing communication competence using an online video reflection system: Preservice teachers' experiences. Asia-Pacific Journal of Teacher Education, 39(4), 311-326.

Boyatzis, R. (1998). Transforming qualitative information: Thematic analysis and code development. Thousand Oaks, CA: Sage Publications.

Campbell, K. S., Mothersbaugh, D. L., Brammer, C., \& Taylor, T. (2001). Peer versus self assessment of oral business presentation performance. Business Communication Quarterly, 64(3), 23-40.

Chan, V. (2011). Teaching oral communication in undergraduate science: Are we doing enough and doing it right? Journal of Learning Design, 4(3), 71-79.
Cheng, W., \& Warren, M. (2005). Peer assessment of language proficiency. Language Testing, 22(1), 93-121.

De Grez, L., Valcke, M., \& Roozen, I. (2009). The impact of an innovative instructional intervention on the acquisition of oral presentation skills in higher education. Computers and Education, 53(1), 112-120.

De Grez, L., Valcke, M., \& Roozen, I. (2012). How effective are selfand peer assessment of oral presentation skills compared with teachers' assessments? Active Learning in Higher Education, 13(2), 129-142.

Dunbar, N. E., Brooks, C. F., \& Kubicka-Miller, T. (2006). Oral communication skills in higher education: Using a performance based evaluation rubric to assess communication skills. Innovative Higher Education, 31(2), 115-128.

Elfering, A., Grebner, S., \& Wehr, S. (2012). Loss of feedback information given during oral presentations. Psychology Learning and Teaching, 11(1), 66-76.

Epstein, M. L., \& Brosvic, G. M. (2002). Students prefer the immediate feedback assessment technique. Psychological Reports, 90(3), 1136-1138.

Han, Y., \& Hyland, F. (2019). Academic emotions in written corrective feedback situations. Journal of English for Academic Purposes, 38, 1-13.

Hattie, J., \& Timperley, H. (2007). The power of feedback. Review of Educational Research, 77(1), 81-112.

Hwang, W.-Y., Shih, T. K., Ma, Z.-H., Shadiev, R., \& Chen, S.-Y. (2016). Evaluating listening and speaking skills in a mobile game-based learning environment with situational contexts. Computer Assisted Language Learning, 29(4), 639-657.

Ko, M.-H. (2019). Students' reactions to using smartphones and social media for vocabulary feedback. Computer Assisted Language Learning, 32(8), 920-944.

Krathwohl, D. R. (2002). A revision of Bloom's Taxonomy: An overview. Theory into Practice, 41(4), 212-218.

Morley, L. (2001). Producing new workers: Quality, equality and employability in higher education. Quality in Higher Education, 7(2), 131-138.

Murillo-Zamorano, L. R., \& Montanero, M. (2018). Oral presentations in higher education: A comparison of the impact of peer and teacher feedback. Assessment and Evaluation in Higher Education, 43(1), 138-150.

Ochoa, X., \& Dominguez, F. (2020). Controlled evaluation of a multimodal system to improve oral presentation skills in a real learning setting. British Journal of Educational Technology, 51(5), 1615-1630.

Phye, G. D., \& Sanders, C. E. (1994). Advice and feedback: Elements of practice for problem solving. Contemporary Educational Psychology, 19(3), 286-301.

Shute, V. J. (2008). Focus on formative feedback. Review of Educational Research, 78(1), 153-189.

Stone, N. (2000). Exploring the relationship between calibration and self-regulated learning. Educational Psychology Review, 12(4), 437-475.

Van Ginkel, S., Gulikers, J., Biemans, H., \& Mulder. M. (2015). The impact of the feedback source on developing oral presentation competence. Studies in Higher Education, 42(9), 1671-1685.

Van Ginkel, S., Gulikers, J., Biemans, H., \& Mulder, M. (2017a). Fostering oral presentation performance: Does the quality of feedback differ when provided by the teacher, peers or peers guided by tutor? Assessment and Evaluation in Higher Education, 42(6), 953-966.

Van Ginkel, S., Gulikers, J., Biemans, H., \& Mulder, M. (2017). The impact of the feedback source on developing oral presentation competence. Studies in Higher Education (Dorchester-onThames), 42(9), 1671-1685. 
Van Ginkel, S., Ruiz, D., Mononen, A., Karaman, C., de Keijzer, A., \& Sitthiworachart, J. (2020). The impact of computer-mediated immediate feedback on developing oral presentation skills: An exploratory study in virtual reality. Journal of Computer Assisted Learning, 36(3), 412-422.

Wang, B., Teo, T., \& Yu, S. (2017). Teacher feedback to student oral presentations in EFL classrooms: A case study. Journal of Education for Teaching, 43(2), 262-264.

Xin, C., \& Feenberg, A. (2006). Pedagogy in cyberspace: The dynamics of online discourse. Journal of Distance Education, $21(2), 1-25$.
Xu, Q., \& Peng, H. (2017). Investigating mobile-assisted oral feedback in teaching Chinese as a second language. Computer Assisted Language Learning, 30(3-4), 173-182.

Xu, Q., Dong, X., \& Jiang, L. (2017). EFL learners' perceptions of mobile-assisted feedback on oral production. TESOL Quarterly, 51(2), 408-417.

Publisher's Note Springer Nature remains neutral with regard to jurisdictional claims in published maps and institutional affiliations. 